\title{
Examining the Psychosocial and Academic Factors Predicting Depression and Anxiety Symptomology Across First-Year and Later-Year University Students
}

\author{
Natalie Eckberg, BPsySc (Hons) \\ Aileen M. Pidgeon, PhD (Clin)
}

Bond University, Gold Coast, Australia

Heidi Magyar, ARNP

University of Florida, Gainesville, Florida, USA

\section{doi: 10.19044/esj.2017.v13n17p1 URL:http://dx.doi.org/10.19044/esj.2017.v13n17p1}

\begin{abstract}
University students across the world report higher levels of mental health problems compared to the general population. Past research has focused on investigating mental health problems among first-year university students. However, a paucity of existing research compares the prevalence of mental health problems in first-year university students to students in later year-levels. To address this gap, the current study compared the level of depression and anxiety symptomology experienced by university students ( $\mathrm{n}$ = 198) from Australia and the United States, across first, second, third, and fourth-year levels. The results found no significant differences in the level of depression and anxiety symptomology between university students from these countries, and no significant differences in the level of depression symptoms across year-levels. However, university students in the secondyear level reported significantly higher levels of anxiety symptoms compared to first, third, and fourth-year levels. The current study assessed the role of stress appraisal, psychosocial, and coping factors as predictors of depression and anxiety symptoms across all year-levels of university students. Hierarchical multiple regressions indicated higher levels of perceived stress and lower levels of perceived social support from family significantly predicted higher levels of depression symptoms. Higher levels of perceived stress and academic avoidance coping, and lower levels of campus connectedness significantly predicted higher levels of anxiety symptoms. Limitations and implications for future research are discussed.
\end{abstract}

Keywords: Depression, anxiety, perceived stress, academic coping, social support, campus connectedness 


\section{Introduction}

Depression and anxiety are recognised as common and debilitating mental health problems among university students, affecting psychological, academic, and social functioning. Previous research has predominantly focused on the psychological adjustment of first-year university students, due to a high reporting of mental health problems among this group (Brandy, Penckofer, Solari-Twadell, \& Velsor-Friedrich, 2015; Cooke, Bewick, Barkham, Bradey, \& Audin, 2006). Individuals between 18 and 34 years of age are considered at greatest risk of developing mental health problems (Stallman, 2010). However, university students report higher rates of negative symptomology compared to age-matched non-students, highlighting there is a need to understand the variables that contribute to poorer psychological well-being among this group (Stallman, 2008).

In Australia, Stallman's (2010) survey of university students $(n=$ 6,479 ) found $83.9 \%$ of the sample reported heightened distress levels. A large study in America $(n=80,121)$ found that university students identify stress as the greatest health-related factor to negatively impact academic performance (The American College Health Association, 2009). A similar prevalence of moderate or higher depression and anxiety symptoms has been found in university students from Australia and America, with higher levels of anxiety symptoms (25-40\%) compared to depression symptoms (23-27\%) (Beiter et al., 2015; Larcombe, Tumbaga, Malkin, Nicholson, \& Tokatlidis, 2013; Rosenthal, Russel, \& Thompson, 2008).

The adverse effects of stress among university students can be debilitating and lead to the development of anxiety and depression symptomology, in addition to poor academic outcomes, student attrition, and suicidal behaviour (Andrews \& Wildling, 2004; Cohen, Kamarck, \& Mermelstein, 1983; Saravanan \& Wilks, 2014). The present study examined the predictive role of stress appraisal, psychosocial, and coping factors on depression and anxiety symptoms to increase understanding of the factors influencing mental health problems among this at-risk group.

\section{First-Year University Students}

The initial adjustment into university life can be distressing for firstyear students, due to a multitude of transitional challenges including adjusting to new living conditions, financial difficulties, and heightened responsibility to succeed academically (Verger et al., 2009). First-year university students have previously reported greater levels of psychological distress compared to students in higher year-levels (Newton-Taylor, Adlaf, Gliksman, \& Demers, 2001). Past research has focused on the prevalence and correlates of mental health problems among first-year students, as this 
group are considered particularly vulnerable to feelings of separation and difficulty adjusting to an unfamiliar environment (Brandy et al., 2015).

Research conducting comparisons between year-levels of students indicates that trends may be changing. Comparing first-year and sixth-year university students’ symptomology has found higher anxiety symptoms to present among first-year students, yet no significant differences in depression symptoms (Bassols et al., 2014). In addition, longitudinal research suggests symptoms of depression and anxiety gradually increase throughout the undergraduate degree (Bewick et al., 2010).

\section{Perceived Stress}

University students' varying abilities to cope with stressors may be explained by individual differences in the perception of stress (Kausar, 2010). In comparison to objective measures of stress (e.g., quantity of stressful life events), perceived stress captures the person-environment interaction by measuring the meaning an individual attributes to a stressor (Cohen et al., 1983; Lazarus, 1991).

Perceived stress is considered a strong predictor of anxiety symptoms among university students (Ghorbani, Krauss, Watson, \& LeBreton, 2008). Systematic review of meta-analyses have provided strong evidence to support the effectiveness of interventions incorporating mindfulness, cognitive, and behavioural methods to alter perceptions of stress and significantly decrease symptoms of anxiety in university students (Regehr, Glancy, \& Pitts, 2013). Other research suggests that university students with symptoms of depression have significantly higher levels of perceived stress compared to those without symptoms (Ramezankhani et al., 2013).

\section{Academic Coping}

The coping strategies employed by university students to manage academic demands can lead to adaptive or maladaptive behaviours. Coping can be defined as the management of internal or external stressors by cognitive or behavioural efforts to reduce demands (Lazarus \& Folkman, 1984). The coping strategies university students employ affect stress management, motivation (Struthers, Perry, \& Menec, 2000), and strongly predict psychopathology in university students (Lazarus \& Folkman, 1984; Watson \& Sinha, 2008). Maladaptive coping mechanisms have been shown to predict higher levels of depression and anxiety symptoms among university students (Mahmoud et al., 2012; Romero et al., 2015). However, little research has explored the relationship between academic styles of coping and depression and anxiety symptoms in University students.. This current study addresses this gap by examining the predictive role of adaptive and maladaptive academic coping strategies on depression and anxiety. 


\section{Social Support}

Help-seeking behaviours among university students are influenced by factors such as stigma related to mental illness, uncertainty of need for help, and uncertainty of treatment effectiveness (Arria et al., 2011). Although universities encourage and typically provide accessible and fee-subsidised mental health services on campus, international data shows university students are unlikely to utilise these resources. Research with Australian university students $(n=384)$ has found $36.3 \%$ of those experiencing high to very high levels of psychological distress had sought treatment (Stallman, 2008). In the United States, $54 \%$ of university students $(n=2,350)$ reporting clinically significant symptoms of depression, anxiety, or suicidal ideation received no treatment in the past year (Eisenberg, Speer, \& Hunt, 2012). Due to the lack of help-seeking behaviours among university students, it is important to examine the role of informal support networks as a potential protective factor for experiencing depression and anxiety symptoms.

Social support can be defined as an individual's sense of reliance on others for emotional support and interpersonal resources (Williams \& Galliher, 2006). Research examining the effect of social support networks on university students' level of depression and anxiety symptoms has yielded inconsistent findings. Investigating first-year students' perceived peer and family social support adequacy has found only a lack of social support from family to significantly predict higher levels of depression symptoms (Brandy et al., 2015). In contrast, other research has found first and second-year university students with both higher peer and parental social support significantly correlated with lower levels of depression (Li, Albert, \& Dwelle, 2014). Students who have partners report fewer mental health problems compared to those without (Eisenberg, Gollust, Golberstein, \& Jennifer, 2007). However, a paucity of studies include significant others when examining perceived peer and family social support adequacy. Multidimensional social support as one factor has shown to have a negative relationship with depression and anxiety symptoms (Zhou, Zhu, Zhang, \& Cai, 2013). However, the effect of each individual support network remains unclear and further research is needed to understand which social networks may act as protective factors for students experiencing depression and anxiety symptoms.

\section{Campus Connectedness}

The term campus connectedness was developed to describe the sense of belongingness university students experience within their campus (Lee \& Davis, 2000). Although campus connectedness has not been widely researched, there is evidence to suggest that social support and social connectedness are two separate constructs, which may predict depression and 
anxiety symptoms in distinct ways. Measures of social connectedness have been shown to mediate the relationship between social support, social competence, and psychological well-being, including depression in university students (Williams \& Galliher, 2006).

Building a positive and supportive campus climate may protect university students from experiencing symptoms of depression (Lindsey, Fabiano, \& Stark, 2009). Campus connectedness has been shown to moderate the relationship between perceived stress and depression, suggesting it may act as a protective factor (Pidgeon, McGrath, Magyar, Stapleton, \& Lo, 2014). Less evidence supports a relationship between social connectedness and anxiety; however, higher social connectedness has been linked to lower trait anxiety in university students (Lee \& Robbins, 1995).

\section{The Current Study}

The current study examined the level of depression and anxiety symptoms experienced across first, second, third, and fourth-year university students, and the role of stress appraisal, academic coping, social support, and campus connectedness as predictors of depression and anxiety symptoms among university students overall.

Hypotheses: H1. First-year university students would report significantly higher levels of depression and anxiety symptoms compared to second, third, and fourth-year university students. H2. Higher levels of perceived stress and academic avoidance coping would significantly predict higher levels of depression and anxiety symptoms. H3. Higher levels of perceived social support (friends, family, and significant others) and campus connectedness would significantly predict lower levels of depression and anxiety symptoms.

\section{Method}

Participants in the current study included 198 students enrolled in tertiary education at an Australian $(n=135)$ and an American $(n=63)$ university. Participants ranged from 18 to 59 years of age $(M=22.04, S D=$ 5.62), consisting of 162 (81.8\%) females and 36 (18.2\%) males. Fifty-eight (29.3\%) first-year university students, 30 (15.2\%) second-year university students, 59 (29.8\%) third-year university students, and 51 (25.8\%) fourthyear university students were recruited.

A brief general demographic questionnaire collected information regarding students' age, gender, degree type, and current year of study.The Depression, Anxiety, and Stress Scale (DASS-21; Lovibond \& Lovibond, 1995) is a 21-item self-report scale designed to measure the negative emotional symptoms of depression, anxiety, and stress. Psychometric analyses have demonstrated that the DASS-21 is an adequately reliable 
(Norton, 2007) and valid (Crawford \& Henry, 2005) measurement. The Perceived Stress Scale (PSS-10; Cohen et al., 1983) is a 10-item self-report scale designed to measure the degree to which one appraises situations in life as stressful. Psychometric analyses have provided adequate reliability and validity evidence for the scale (Roberti, Harrington, \& Storch, 2006).. The Academic Coping Strategies Scale (ACSS; Sullivan, 2010) is a 34-item selfreport scale designed to measure university students' coping strategies in response to an academic stressor (receiving a grade lower than expected). The scale contains three subscales: Approach, Avoidance, and Social Support. Each subscale has demonstrated adequate reliability and validity by correlating with other scales of self-regulation and performance avoidance in the expected direction (Sullivan, 2010). Higher scores on the Approach and Social Support subscales indicate higher levels of adaptive academic coping and higher scores on the Avoidance subscale indicate higher levels of maladaptive academic coping. The Multidimensional Scale of Perceived Social Support (MSPSS; Zimet, Dahlem, Zimet, \& Farley, 1988) is a 12-item self-report scale designed to measure social support adequacy across three networks: family, friends, and significant other. Each subscale of the MSPSS has demonstrated adequate reliability (Bruwer et al., 2008) and validity by correlating with other scales of social support in the expected direction (Kazarian \& McCabe, 1991). The Campus Connectedness Scale (CCS; Lee \& Davis, 2000; Lee \& Robbins, 1995; Summers, Svinicki, Gorin, \& Sullivan, 2002) is a 14-item self-report scale designed to measure university students' psychosocial sense of belonging to their campus environment (Lee \& Davis, 2000). The CCS has demonstrated adequate reliability and validity (Sulkowski, 2011).

This research was approved by the Bond University Human Research Ethics Committee. A non-probability, convenience sampling method was used to recruit participants. The 30-minute questionnaire package was administered and participants were informed of all relevant ethical considerations and participated voluntarily.

\section{Results}

Preliminary between-subjects analyses of variance indicated there were no significant pre-existing differences between university students from Australia and America on depression $(F(1,196)=.78, p=.38)$ or anxiety $(F(1,196)=2.35, p=.13)$ symptoms. Consequently, it was appropriate to merge the data files and conduct subsequent analyses with an international sample. 


\section{Descriptive Statistics}

Table 1 below displays Pearson's correlations, means and standard deviations for the predictors and dependent variables.

In the current sample $16.2 \%(\mathrm{n}=32)$ of university students experienced moderate or greater levels of depression symptoms and $24.7 \%$ $(n=49)$ experienced moderate or greater levels of anxiety symptoms.

Table 1

\begin{tabular}{|c|c|c|c|c|c|c|c|c|c|c|c|c|}
\hline Measure & 1 & 2 & 3 & 4 & 5 & 6 & 7 & 8 & 9 & 10 & $M$ & $S D$ \\
\hline 1. PSS & $\cdot$ & $-.41^{* *}$ & $.39 * *$ & -.02 & $-22^{* *}$ & $-29 * *$ & $.16^{*}$ & $.46^{* *}$ & $.57^{* *}$ & $.52 * *$ & 17.98 & 5.87 \\
\hline 2. $A C A P$ & & . & $-43^{* *}$ & $.41 *$ & $.36^{* *}$ & $.41 *$ & $.29 \bullet$ & $.35 * *$ & $-29 \cdot *$ & $-24 * *$ & 57.84 & 8.48 \\
\hline 3. $\mathrm{AC} \cdot \mathrm{AV}$ & & & - & .06 & -.12 & -.08 & .08 & $-.28 * *$ & $.36 * *$ & $.38 * *$ & 27.63 & 7.21 \\
\hline 4.AC.SS & & & & - & $.30 * *$ & $.33 * *$ & $.26^{* *}$ & $.26^{* *}$ & -.08 & .06 & 27.09 & .34 \\
\hline 5. Ss-FAM & & & & & - & $.47 * *$ & $.54 * *$ & $.27 * *$ & $-29 * *$ & -.07 & 5.96 & 1.01 \\
\hline 6. SS-FRI & & & & & & . & $.49 *$ & $.56 * *$ & $-28 * \bullet$ & $.20^{* *}$ & 5.83 & 1.02 \\
\hline 7. ss.so & & & & & & & . & $.20^{* *}$ & $.19 \bullet$ & .09 & 6.05 & 1.10 \\
\hline 8. Cc & & & & & & & & . & $-39 * *$ & $-38 * *$ & 59.61 & 11.86 \\
\hline 9. Depression & & & & & & & & & . & $.52 *$ & 6.11 & 6.41 \\
\hline 10. Anxiety & & & & & & & & & & . & 6.15 & 5.95 \\
\hline
\end{tabular}

Note. $* p<.05, * p<$.01, *** $p<001$. PSS = Perceived Stress Scale. AC-AP = Approach Academic Coping. AC-AV = Avoidance Academic Coping. AC-SS = Social Support Academic

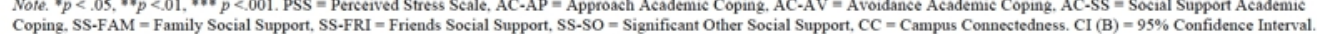
Coping.
$N=198$

\section{Multivariate Analysis of Variance (MANOVA)}

The results from the MANOVA showed that there were no significant differences between year-level (first, second, third, and fourthyear) on the combined dependent variables $F(6,388)=1.61, p=.15$. There were no significant differences between year-level on symptoms of depression, $F(3,194)=1.52, p=.21$. However, there were significant differences between year-level and symptoms of anxiety $F(3,194)=3.10, p$ $=.03$, partial $\eta^{2}=.05$, Power $=>1$. Tukey B's post-hoc tests indicated that second-year university students' symptoms of anxiety $(M=9.13, S D=6.90)$ were significantly higher than first-year $(M=5.70, S D=5.62)$, third-year $(M$ $=5.39, S D=5.37)$, and fourth-year $(M=5.80, S D=6.00)$ university students' symptoms of anxiety.

A hierarchical multiple regression for depression symptoms was performed with the predictors perceived stress, academic coping, social support, and campus connectedness. At Step 1, perceived stress was entered and the model was significant $F(1,196)=95.39, p<.001$, suggesting that perceived stress accounted for $32 \%$ of the variance in depression symptoms. 
At Step 2, academic coping (approach, avoidance, and social support) was entered and the model remained significant, $F(4,193)=25.79, p<.001$. However, academic coping did not significantly contribute to the model $\Delta F(3,193)=2.07, p=.11$. At Step 3, social support (family, friends, and significant other) was entered and the model remained significant $F(7,190)$ $=16.36, p<.001$. Social support significantly contributed to the model $\Delta F(3$, $190)=2.82, p=.04$, suggesting that social support (family) accounted for an additional $3 \%$ of the variance in depression symptoms. At Step 4, campus connectedness was entered and the model remained significant $F(8,189)=$ $14.72, p<.001$. However, campus connectedness did not significantly contribute to the model $\Delta F(1,189)=2.40, p=.12$. Overall, the independent variables accounted for $36 \%$ of the total variance in the criterion, depression symptoms. As seen in Table 2, higher levels of perceived stress were predictive of higher levels of depression symptoms and higher levels of family social support were predictive of lower levels of depression symptoms.

A hierarchical multiple regression for anxiety symptoms was performed with the predictors perceived stress, academic coping, social support, and campus connectedness. At Step 1, perceived stress was entered and the model was significant $F(1,196)=72.14, p<.001$, suggesting that perceived stress accounted for $27 \%$ of the variance in anxiety symptoms. At Step 2, academic coping (approach, avoidance, and social support) was entered and the model remained significant, $F(4,193)=21.64, p<.001$. Academic coping (avoidance) significantly contributed to the model $\Delta F(3$, $193)=3.79, p=.01$, accounting for an additional $4 \%$ of the variance in anxiety symptoms. At Step 3, social support (family, friends, and significant other) was entered and the model remained significant $F(7,190)=12.91, p$ $<.001$. However social support did not significantly contribute to the model $\Delta F(3,190)=1.18, p=.32$. At Step 4 , campus connectedness was entered and the model remained significant $F(8,189)=12.31, p<.001$. Campus connectedness significantly contributed to the model $\Delta F(1,189)=5.83, p=$ .02 , accounting for an additional $2 \%$ of the variance in anxiety symptoms. Overall, the independent variables accounted for $32 \%$ of the total variance in the criterion, anxiety symptoms. Ss seen in Table 3 below, higher levels of perceived stress and academic avoidance coping were predictive of higher levels of anxiety symptoms. Higher levels of campus connectedness were predictive of lower levels of anxiety symptoms. 
Table 2

Hierarchical Multiple Regression Coefficients for Perceived Stress, Academic Coping, Social Support , and Campus Connectedness as Predictors of Depression

\begin{tabular}{|c|c|c|c|c|c|c|c|}
\hline & Predictors & $\begin{array}{c}\text { Adjusted } \\
R^{2}\end{array}$ & $\Delta R^{2}$ & $B$ & SEB & $\beta$ & CI (B) \\
\hline \multirow[t]{3}{*}{ Step 1} & & $.32 * * *$ & .33 & & & & \\
\hline & Constant & & & $-5.89 * * *$ & 1.21 & & \\
\hline & PSS & & & $.63 * * *$ & .06 & .57 & {$[.50, .75]$} \\
\hline \multirow[t]{6}{*}{ Step 2} & & .34 & .03 & & & & \\
\hline & Constant & & & -5.67 & 4.16 & & \\
\hline & PSS & & & $.57 * * *$ & .07 & .52 & {$[.43, .71]$} \\
\hline & AC-AP & & & .01 & .06 & .02 & {$[-.10, .13]$} \\
\hline & AC-AV & & & $.13 *$ & .06 & .14 & {$[.01, .25]$} \\
\hline & AC-SS & & & -.10 & .08 & -.09 & {$[-.26, .05]$} \\
\hline \multirow[t]{9}{*}{ Step 3} & & $.35 *$ & .03 & & & & \\
\hline & Constant & & & -1.16 & 4.44 & & \\
\hline & PSS & & & $.53 * * *$ & .07 & .49 & {$[.39, .67]$} \\
\hline & AC-AP & & & .06 & .06 & .08 & {$[-.06, .18]$} \\
\hline & AC-AV & & & $.14^{*}$ & .06 & .16 & {$[.02, .26]$} \\
\hline & AC-SS & & & -.05 & .08 & -.04 & {$[-.21, .12]$} \\
\hline & SS-FAM & & & $-.93 *$ & .46 & -.15 & {$[-1.83,-.02]$} \\
\hline & SS-FRI & & & -.55 & .46 & -.09 & {$[-1.45, .36]$} \\
\hline & SS-SO & & & .09 & .42 & .02 & {$[-.73, .91]$} \\
\hline \multirow{10}{*}{ Step 4} & & .36 & .01 & & & & \\
\hline & Constant & & & 1.74 & 4.81 & & \\
\hline & PSS & & & $.49 * * *$ & .08 & .45 & {$[.34, .64]$} \\
\hline & AC-AP & & & .05 & .06 & .07 & {$[-.06, .17]$} \\
\hline & AC-AV & & & $.13 *$ & .06 & .15 & {$[.01, .25]$} \\
\hline & AC-SS & & & -.03 & .08 & -.03 & {$[-.19, .13]$} \\
\hline & SS-FAM & & & $-.93 *$ & .46 & -.15 & {$[-1.84,-.03]$} \\
\hline & SS-FRI & & & -.18 & .52 & -.03 & {$[-1.20, .83]$} \\
\hline & SS-SO & & & .01 & .42 & .00 & {$[-82, .83]$} \\
\hline & CC & & & -.06 & .04 & -.12 & {$[-.15, .02]$} \\
\hline
\end{tabular}

Note. $* p<.05, * * p<.01, * * * p<.001$. PSS $=$ Perceived Stress Scale, AC-AP $=$ Approach Academic Coping, AC-AV = Avoidance Academic Coping, AC-SS $=$ Social Support Academic Coping, SS-FR = Friends Social Support, SS-FAM = Family Social Support, SS-SO = Significant Other Social Support, CC $=$ Campus Connectedness. CI (B) $=95 \%$ Confidence Interval

Table 3

Hierarchical Multiple Regression Coefficients for Perceived Stress, Academic Coping, Social Support, and Campus Connectedness as Predictors of Anxiety

\begin{tabular}{|c|c|c|c|c|c|c|c|}
\hline & Predictors & Adjusted $R^{2}$ & $\Delta R^{2}$ & $B$ & SEB & $\beta$ & CI (B) \\
\hline Step 1 & & $.27^{* * *}$ & .27 & & & & \\
\hline \multirow{5}{*}{ Step 2} & Constant & \multirow{5}{*}{$.30^{*}$} & \multirow{5}{*}{.04} & $-3.30 * *$ & 1.17 & & \\
\hline & PSS & & & $.53 * * *$ & .06 & .52 & {$[.40, .65]$} \\
\hline & & & & & & & \\
\hline & Constant & & & $-8.79 *$ & 3.97 & & \\
\hline & PSS & & & $.45 * * *$ & .07 & .44 & {$[.31, .59]$} \\
\hline \multirow{7}{*}{ Step 3} & AC-AP & \multirow{7}{*}{.30} & \multirow{7}{*}{.01} & .01 & .06 & .01 & {$[-.10, .12]$} \\
\hline & AC-AV & & & $.17 * *$ & .06 & .21 & {$[.06, .29]$} \\
\hline & AC-SO & & & .06 & .08 & .05 & {$[-.09, .21]$} \\
\hline & & & & & & & \\
\hline & Constant & & & -8.14 & 4.30 & & \\
\hline & PSS & & & $.43 * * *$ & .07 & .43 & {$[.29, .57]$} \\
\hline & AC-AP & & & .02 & .06 & .03 & {$[-.09, .14]$} \\
\hline
\end{tabular}




\begin{tabular}{|c|c|c|c|c|c|c|c|}
\hline & AC-AV & & & $.18^{* *}$ & .06 & .22 & {$[.07, .30]$} \\
\hline & AC-SS & & & .07 & .08 & .07 & {$[-.08, .23]$} \\
\hline & SS-FAM & & & .48 & .45 & .08 & {$[-.40,1.36]$} \\
\hline & SS-FRI & & & -.76 & .45 & -.13 & {$[-1.64, .12]$} \\
\hline & SS-SO & & & -.03 & .40 & -.01 & {$[-.82, .77]$} \\
\hline \multirow[t]{10}{*}{ Step 4} & & $.32 *$ & .02 & & & & \\
\hline & Constant & & & -3.81 & 4.61 & & \\
\hline & PSS & & & $.37 * * *$ & .07 & .37 & {$[.23, .52]$} \\
\hline & AC-AP & & & .02 & .06 & .02 & {$[-.10, .13]$} \\
\hline & AC-AV & & & $.17^{* *}$ & .06 & .20 & {$[.05, .28]$} \\
\hline & AC-SS & & & .11 & .08 & .10 & {$[-.05, .26]$} \\
\hline & SS-FAM & & & .46 & .44 & .08 & {$[-.41,1.33]$} \\
\hline & SS-FRI & & & -.21 & .49 & -.04 & {$[-1.19, .76]$} \\
\hline & SS-SO & & & -.15 & .40 & -.03 & {$[-.95, .64]$} \\
\hline & CC & & & $-.10^{*}$ & .04 & -.19 & {$[-.17,-.02]$} \\
\hline
\end{tabular}

Note. $* p<.05, * * p<.01, * * * p<.001$. PSS $=$ Perceived Stress Scale, AC-AP $=$ Approach Academic Coping, AC-AV = Avoidance Academic Coping, AC-SS = Social Support Academic Coping, SS-FR = Friends Social Support, SS-FAM = Family Social Support, SS-SO = Significant Other Social Support, CC $=$ Campus Connectedness. CI (B) $=95 \%$ Confidence Interval

\section{Discussion}

Overall, the current study found that students experienced a higher level of anxiety symptoms compared to depression symptoms, a finding that has been reported among university students internationally (Beiter et al., 2015; Larcombe et al., 2013; Rosenthal et al., 2008). Compared to prevalence rates of depression and anxiety symptoms across university students in other countries, the current sample had lower prevalence rates. However, this may have been attributable to other variables such as the smaller sample size used and the differences in recording methods of depression and anxiety symptoms across the research.

The results of the present study found the first hypothesis was not supported, in that there were no significant differences in the level of depression symptoms reported by first, second, third, and fourth-year university students from both universities. This finding is in contrast with previous research, which indicated that first-year university students were most vulnerable to experiencing high levels of mental health problems (Newton-Taylor et al., 2001).

A significant finding of the present study was that second-year university students reported significantly higher anxiety symptoms compared to first, third, and fourth-year university students. An explanation for this finding on anxiety may be that second-year university necessitates heightened academic demands in comparison to the first-year of study, provoking symptoms of anxiety. However, these results need to be interpreted cautiously, as a limitation of this study was that fewer secondyear university students in the sample compared to other year-levels.

The results from the current study revealed that only one factor, perceived stress, significantly predicted both depression and anxiety 
symptoms. In contrast with previous findings (Ghorbani et al., 2008; Regehr et al., 2013), perceived stress was a stronger predictor of depression when compared to anxiety symptoms. Perceived stress was the strongest predictor overall, suggesting university students' appraisal of daily stressors has a considerable impact on depression and anxiety symptoms, consistent with previous research (Cohen et al., 1983). This may encourage universities to consider stress reduction programs that focus on changing the appraisal of stress, such as mindfulness-based interventions (Regehr et al., 2013).

The current study found maladaptive academic coping (avoidance coping) significantly and positively correlated with depression and anxiety symptoms, supporting previous research (Mahmoud et al., 2012; Romero et al., 2015). However, the results from the present study showed that academic avoidance coping significantly predicted only anxiety symptoms, providing partial support for the second hypothesis. As expected, adaptive academic coping mechanisms (social support and approach academic coping) were not significant predictors, suggesting they may not act as protective factors for depression and anxiety symptoms.

The findings of the current study were consistent with previous research indicating that higher perceived social support from family significantly predicted the lower levels of depression symptoms experienced by university students (Brandy et al. 2015). This suggests social support from family may be a protective factor against depression. Overall, multidimensional social support was not a strong predictor in the current study; however, the results do provide support for future research to examine the predictability of individual social support networks separately.

Higher levels of campus connectedness significantly predicted lower levels of anxiety symptoms, inconsistent with previous findings (Pidgeon et al., 2014; Williams \& Galliher, 2006). The broader concept of campus connectedness was a significant predictor of anxiety, and social support from family was a significant predictor of depression symptoms. Future research could examine social support and social connectedness as separate constructs, as university students who lack a sense of connectedness to the university campus and community may be considered at greater risk of developing anxiety symptoms.

The findings of the current study should be interpreted within the context of its limitations. A large majority of the participants in the current study were females (81.8\%) and the results may be subject to gender bias. The current study recruited a sample of students from Australia and the United States to increase generalizability to an international university student population. However, these populations predominantly reflect Western culture, and therefore it is unclear to what extent these findings can be generalized or implemented cross-culturally. Finally, as the data collected 
was based on self-report methods, social desirability bias may have been activated due to negative stigmatization of mental health problems among university students, potentially causing the underreporting of symptom severity.

Overall, findings from the current study highlight that academic and psychosocial factors each contribute uniquely to depression and anxiety symptoms. Significant predictors of higher depression symptoms included higher perceived stress and lower levels of social support from family. Contrastingly, higher perceived stress and academic avoidance coping, and lower levels of campus connectedness significantly predicted higher symptoms of anxiety.

Broadening the focus to university students across all year-levels may be a feasible direction for future research to encompass a larger proportion of university students affected by psychological morbidity. Longitudinal studies may provide further insight into critical time points at which university students are at greatest risk. Addressing a persisting high prevalence of depression and anxiety symptoms among this group requires furthering current understanding and clearly identifying risk and protective factors currently contributing to mental health problems. This will assist education providers in improving the psychological, academic, and social aspects of the university experience and improve psychological well-being in university students.

\section{References:}

1. American College Health Association (2009). American college health association-national college health assessment spring 2008 reference group data report (abridged). Journal of American College Health, 57, 477. doi: 10.3200/JACH.57.5.477-488.

2. Andrews, B., \& Wildling, J. M. (2004). The relation of depression and anxiety to life- stress and achievement in students. British Journal of Psychology, 95, $509 . \quad$ doi:

10.1348/0007126042369802.

3. Arria, A. M., Winick, E. R., Garnier-Dykstra, L. M., Vincent, K. B., Caldeira, K. M., Wilcox, H. C., \& O’Grady, K. E. (2011). Helpseeking and mental health service utilization among college students with a history of suicide ideation. Psychiatric Services, 62, 1510-1513.

4. Bassols, A. M., Okabayashi, L. S., Silva, A. B., Carneiro, B. B., Feijó, F., Guimarães, G. C., Cortes, G. N., Rohde, L. A., \& Eizirik, C. L. (2014). First- and last- year medical students: Is there a difference in the prevalence and intensity of anxiety and depressive 
symptoms? Journal of Psychiatry, 36, 233-240. doi:10.1590/15164446-2013-1183

5. Beiter, R., Nash, R., McCrady, M., Rhoades, D., Linscomb, M., Clarahan, M., \& Sammut, S. (2015). The prevalence and correlates of depression, anxiety, and stress in a sample of college students. Journal of Affective Disorders, 173, 90-96. doi: 10.1016/j.jad.2014.10.054

6. Bewick, B., Koutsopoulou, G., Miles, J., Slaa, E., \& Barkham, M. (2010). Changes in undergraduate students' psychological well being as they progress through university. Studies in Higher Education, 35, 633-645. doi: 10.1080/03075070903216643

7. Brandy, J. M., Penckofer, S., Solari-Twadell, P. A., \& VelsorFriedrich, B. (2015). Factors predictive of depression in first-year college students. Journal of Psychosocial Nursing and Mental Health Services, 53, 38-44. doi:10.3928/02793695-20150126-03

8. Bruwer, B., Emsley, R., Kidd, M., Lochner, C., \& Seedat, S. (2008). Psychometric properties of the multidimensional scale of perceived social support in youth. Comprehensive Psychiatry, 49, 195-201. doi:10.1016/j.comppsych.2007.09.002

9. Cohen, S., Kamarck, T., \& Mermelstein, R. (1983). A global measure of perceived stress. Journal of Health and Social Behaviour, 24, 385396. doi: 10.2307/2136404

10. Cooke, R., Bewick, B. M., Barkham, M., Bradley, M., \& Audin, K. (2006). Measuring, monitoring, and managing the psychological well-being of first year university students. British Journal of Guidance \& Counseling, 34, 505-517. doi:10.1080/03069880600942624

11. Crawford, J. R., \& Henry, J. D. (2003). The depression anxiety stress scales (DASS): Normative data and latent structure in a large nonclinical sample. British Journal of Clinical Psychology, 42, 111-131. doi:10.1348/014466503321903544

12. Eisenberg, D., Gollust, S. E., Golberstein, E., \& Jennifer, L. H. (2007). Prevalence and correlates of depression, anxiety, and suicidality among university students. American Journal of Orthopsychiatry 77, 534-542. doi: 10.1037/0002- 9432.77.4.534

13. Eisenberg, D., Speer, N., \& Hunt, J. B. (2012). Attitudes and beliefs about treatment among college students with untreated mental health problems. Psychiatric Services, 63, 711-713. doi:10.1176/appi.ps.201100250

14. Ghorbani, N., Krauss, S. W., Watson, P. J., \& LeBreton, D. (2008). Relationship of perceived stress with depression: Complete mediation by perceived control and anxiety in Iran and the United States. 
International Journal of Psychology, 43, 958-968. doi:10.1080/00207590701295264

15. Kausar, R. (2010). Perceived stress, academic workloads and use of coping strategies by university students. Journal of Behavioural Sciences, 20, 31.

16. Kazarian, S. S., \& McCabe, S. B. (1991). Dimensions of social support in the MSPSS: Factorial structure, reliability, and theoretical implications. Journal of Community Psychology, 19, 150-160.

17. Larcombe, W., Tumbaga, L., Malkin, I., Nicholson, P., \& Tokatlidis, O. (2013). Does an improved experience of law school protect students against depression, anxiety and stress? An empirical study of wellbeing and the law school experience of LLB and JD students. Sydney Law Review, 35, 407-432.

18. Lazarus, R. S., \& Folkman, S. (1984). Stress, appraisal, and coping. New York: Springer Pub. Co.

19. Lazarus, R. S. (1991). Progress on a cognitive-motivational-relational theory of emotion. American Psychologist, 46, 819-834. doi:10.1037/0003-066X.46.8.819

20. Lee, R. M., \& Davis, C. D. (2000). Cultural orientation, past multicultural experience, and a sense of belonging on campus for Asian-American college students. Journal of College Student Development, 41, 110-115.

21. Lee, R. M., \& Robbins, S. B. (1995). Measuring belongingness: The Social Connectedness and the Social Assurance Scales. Journal of Counselling Psychology, 42, 232-241. doi: 10.1037-00220167.42.2.232

22. Lindsey, B. J., Fabiano, P., \& Stark, C. (2009). The prevalence and correlates of depression among college students. College Student Journal, 43, 999. doi: 10.1016/j.jad.2014.10.054

23. Li, S. T., Albert, A. B., \& Dwelle, D. G. (2014). Parental and peer support as predictors of depression and self-esteem among college students. Journal of College Student Development, 55, 120-138. doi: 10.1353/csd.2014.0015

24. Lovibond, S.H., \& Lovibond, P.F. (1995). Manual for the Depression Anxiety and Stress Scales. Sydney, Australia: Psychological Foundation.

25. Mahmoud, J. S. R., Staten, R. T., Hall, L. A., \& Lennie, T. A. (2012). The relationship among young adult college students' depression, anxiety, stress, demographics, life satisfaction, and coping styles. Issues in Mental Health Nursing, 33, 149-156. doi:10.3109/01612840.2011.632708 
26. Newton-Taylor, B., Adlaf, E., Gliksman, L., \& Demers, A. (2001). The prevalence of elevated psychological distress among Canadian undergraduates: Findings from the 1998 Canadian campus survey. Journal of American College Health, 50, 67-72. doi:10.1080/07448480109596009

27. Norton, P. (2007). Depression anxiety and stress scales (DASS-21): Psychometric analysis across four racial groups. Anxiety, Stress \& Coping, 20, 253-265. doi:10.1080/10615800701309279

28. Pidgeon, A. M., McGrath, S., Magyar, H., Stapleton, P. B., \& Lo, B. (2014). Psychosocial moderators of perceived stress, anxiety and depression in university students: An international study. Open Journal of Social Sciences, 2, 23-31. doi: 10.4236/jss.2014.211004

29. Ramezankhani, A., Gharlipour, Z., Heydarabadi, A. B., Tavassoli, E., Motalebi, M., Barekati, H., Gilasi, H. R., Ranjbar, T. K., \& Moosavi, S. A. (2013). Perceived social support, depression, and perceived stress in university students. Journal of Paramedical Sciences, 4, 3136. Retrieved

from:

http://journals.sbmu.ac.ir/jps/article/view/4846/4299

30. Regehr, C., Glancy, D., \& Pitts, A. (2013). Interventions to reduce stress in university students: A review and meta-analysis. Journal of Affective Disorders, 148, 1- 11. doi: 10.1016/j.jad.2012.11.026

31. Roberti, J. W., Harrington, L. N., \& Storch, E. A. (2006). Further psychometric support for the 10-item version of the perceived stress scale. Journal of College Counseling, 9, $135 . \quad$ doi: 10.1002/j.2161-1882.2006.tb00100.x

32. Romero, D. H., Riggs, S. A., \& Ruggero, C. (2015). Coping, family social support, and psychological symptoms among student veterans. Journal of Counseling Psychology, 62, 242-252. doi:10.1037/cou0000061

33. Rosenthal, D. A., Russell, J., \& Thomson, G. (2008). The health and wellbeing of international students at an Australian university. Higher Education, 55, 51- 67. doi:10.1007/s10734-006-9037-1

34. Saravanan, C., \& Wilks, R. (2014). Medical students' experience of and reaction to stress: The role of depression and anxiety. Scientific World Journal, 1-8. doi:10.1155/2014/737382

35. Stallman, H. M. (2008). Prevalence of psychological distress in university students: Implications for service delivery. Australian Family Physician, 37, 673-677. Retrieved from: http://search.proquest.com/docview/216302474?accountid=26503

36. Stallman, H. M. (2010). Psychological distress in university students: A comparison with general population data. Australian Psychologist, 45, 249-257. doi.org/10.1080/00050067.2010.482109 
37. Struthers, C. W., Perry, R. P., \& Menec, V. H. (2000). An examination of the relationship among academic stress, coping, motivation, and performance in college. Research in Higher Education, 41, 581-592.

38. Sulkowski, M. L. (2011). An investigation of students' willingness to report threats of violence in campus communities. Psychology of Violence, 1, 53. doi: 10.1037/a0021592

39. Sullivan, J. R. (2010). Preliminary psychometric data for the Academic Coping Strategies Scale. Assessment for Effective Intervention, 35, 114-127. doi:10.1177/1534508408327609

40. Summers, J. J, Svinicki, M. D., Gorin, J. S., \& Sullivan, T. A. (2002). Student feelings of connection to the campus and openness to diversity and challenge at a large research university: Evidence of Progress? Innovative Higher Education, 27, 53-64. doi: 10.1.1.123.9951

41. Verger, P., Combes, J., Kovess-Masfety, V., Choquet, M., Guagliardo, V., Rouillon, F., \& Peretti-Wattel, P. (2009). Psychological distress in first year university students: Socioeconomic and academic stressors, mastery and social support in young men and women. Social Psychiatry and Psychiatric Epidemiology, 44, 643-650. doi:10.1007/s00127-008-0486-y

42. Watson, D. C., \& Sinha, B. (2008). Emotion regulation, coping, and psychological symptoms. International Journal of Stress Management, 15, 222-234. doi:10.1037/1072-5245.15.3.222

43. Williams, K. L., \& Galliher, R. V. (2006). Predicting depression and self-esteem from social connectedness, support, and competence. Journal of Social and Clinical Psychology, 25, 855-874.

44. Zhou, X., Zhu, H., Zhang, B., \& Cai, T. (2013). Perceived social support as moderator of perfectionism, depression, and anxiety in college students. Social Behavior and Personality, 41, 1141-1152. doi: 10.2224/sbp.2013.41.7.1141

45. Zimet, G. D., Dahlem, N. W., Zimet, S. G., \& Farley, G. K. (1988). The Multidimensional Scale of Perceived Social Support. Journal of Personality Assessment, 52, 30. doi: 10.1207/s15327752jpa5201_2 